\title{
Plow for processing row spacing of gardens
}

\author{
Laziz Babajanov $^{1 *}$, Zayniddin Sharipov ${ }^{1}$, Bakhodir Khakimov ${ }^{1}$, Sunnat Badalov ${ }^{2}$ and Eldor \\ Sobirov $^{3}$ \\ ${ }^{1}$ Tashkent Institute of Irrigation and Agricultural Mechanization Engineers, Tashkent, Uzbekistan \\ ${ }^{2}$ Karshi Engineering Economic Institute, Karshi, Uzbekistan \\ ${ }^{3}$ Karshi branch of Tashkent Institute of Irrigation and Agricultural Mechanization Engineers, Karshi, \\ Uzbekistan
}

\begin{abstract}
Existing plows do not provide high-quality tillage between rows of orchards and vineyards. The purpose of the study is to develop and justify the parameters of the plow for cultivating the soil between rows of gardens to tractors of class $0.9 \mathrm{kN}$. A design scheme of a single-body plow for smooth, rowless plowing of garden aisles has been developed. The proposed plow consists of a movable and fixed frame, a disc knife, a screw body with a hostage. The research uses the laws of agricultural mechanics, mathematical statistics, and methods of strain measurement. The technology of cultivating the soil between rows of gardens with a singlebody plow for smooth plowing is justified. To implement the proposed technology, the position of the plow body changes relative to the tractor during operation. It is established that when equipping a plow with a movable and fixed frame and performing a body width of $45-52.5 \mathrm{~cm}$, the required plowing quality is achieved with the lowest energy consumption.
\end{abstract}

\section{Introduction}

In the agricultural production of the Republic of Uzbekistan, large-scale measures are being taken to reduce labor and energy costs, save resources and develop high-performance agricultural machines; in particular, special attention is paid to the development of technical means that ensure the high-quality implementation of all technological processes of crop cultivation from tillage to harvesting and processing of products [1-23].

It is known that to improve the water-air regime, therefore, for the normal development of garden plantations and vineyards and increase their productivity, plowing between rows is carried out annually with serial plows. The disadvantage of serial plows used in horticulture is the formation of collapse furrows and pile ridges due to the turnover of the reservoir in the neighboring furrow. These irregularities worsen the working conditions of the units during subsequent processing. V.Sakun [6, 14-15], Ya.Lobachevsky [6-7, 9-10, 12-15], V.Sharov [6, 11], O.Sizov [6, 15], F.Mamatov [19-24], I.Ergashev [24], B.Mirzaev [19-20, 22-23], N.Aldoshin [22-24], H.Ravshanov [25-26] and others.

However, in these studies, the issues of developing a plow for smooth plowing for

\footnotetext{
*Corresponding author: laziz.bk@bk.ru
} 
tractors of class $0.9 \mathrm{kN}$ are not sufficiently studied.

The purpose of the study is to develop and justify the parameters of the plow for cultivating the soil between rows of gardens to tractors of class $0.9 \mathrm{kN}$.

\section{Methods}

The research uses the laws of agricultural mechanics, mathematical statistics, and methods of strain measurement. The technology of cultivating the soil between rows of gardens with a single-body plow for smooth plowing is justified.

Based on the analysis of research, plowing technologies and equipment in developed countries, and agrotechnical requirements for the main tillage plow between the rows, a structural scheme of a single-plow flat tillage plow between rows and small contour fields was developed (Figure 1).

The single-body hollow flat plow consists of a main frame 1 , a moving frame 2 , a suspension device 3, a support wheel 4 , a disc blade 5, a screw body 6 , a piston 7 , a hydraulic motor 8, a chain extension 9 and a screw 10 (2.1, $a, b$ and $v$-pictures). The plug can be equipped with a roller if necessary. The working bodies of the plug are mounted on the movable frame 2. Depending on the machined path of the row spacing, the position of the moving frame 2 is changed using a screw mechanism 5 relatives to the main frame 1 . In this case, the moving frame 2 slides along the aisle in the main frame 1 . The movement of the propeller mechanism to the screw 10 is transmitted from the hydraulic motor 8 through the chain drive 9 . Using a helical mechanism, the housing can slide from the right edge to the left edge up to $3 b_{k}$ (Fig.1).

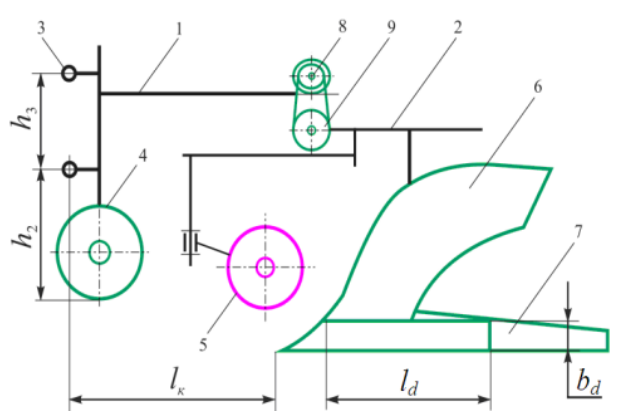

a)

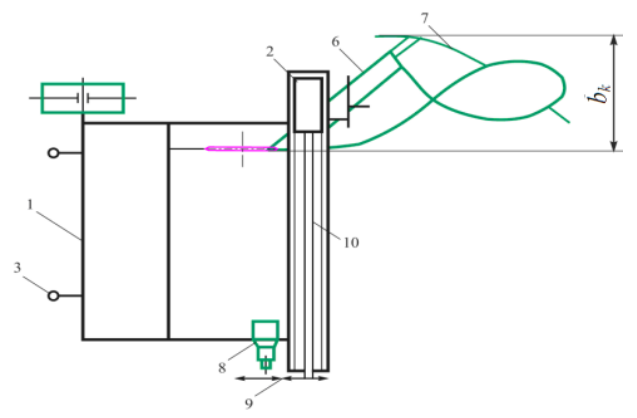

b)

Fig. 1. Design diagram of a single-body plow for smooth plowing: $a$ - side view: $b$ is top view; 1 is main frame; 2 is movable frame; 3 is attachment; 4 is support wheel; 5 is disc knife; 6 is body; 7 is plow; 8 is hydraulic motor; 9 is chain drive; 10 is screw

The technological work process of the plow in the cultivation of garden spaces and small contour fields is as follows. In the first transition, the housing is in the most extreme position on the right side of the frame (Figures 1,b, and 2,a). The soil is cut in the vertical plane with the blades 3 , and in the horizontal plane with the lemex of the main body 1 , resulting in a slab with a "half cut" of $35-70 \mathrm{~mm}$. The main body is first independent and then interacts with the zaplujnik 2, rotating the palach and laying 1800 on the boundary of its owner. When the drive unit returns from the field, the body is in the right position relative to the frame (Fig. 2,a) and performs the plowing process as described above. In subsequent passes of the unit, the plug handles between the rows. In this case, the body is moved a certain transverse distance relative to the tractor. 


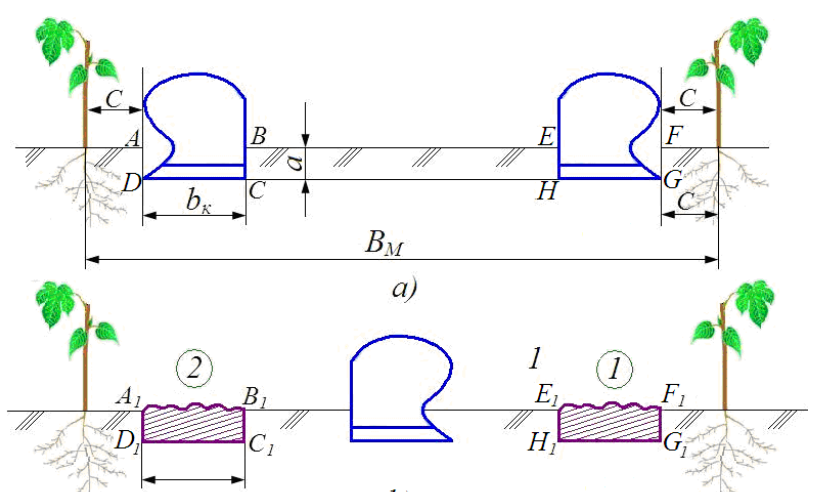

b)
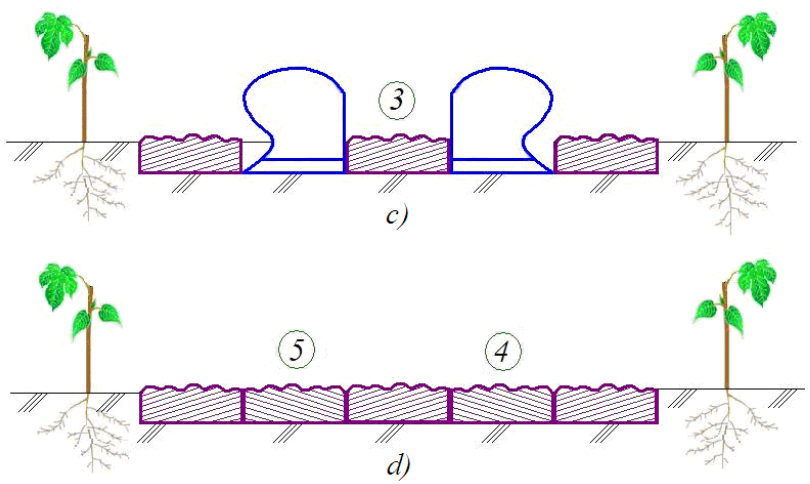

Fig. 2. Technology of soil cultivation between rows of gardens: $a$ is type of row-spacing before the passage of the unit; $b$ is view of the row spacing after the first and second passes of the unit; $\mathrm{c}$ is view of the row spacing after the third pass of the unit; $d$ is type of row spacing after the fourth and fifth passes of the unit

The number of passes and the transverse displacement distance associated with it depend on the garden row spacing width. The largest transverse shear size of the plug body is $3 b_{k}$, where bk is the coverage width of the body. Thus, flat plowing of small garden spaces and small contoured plots is carried out. When working the soil between the gardens with a row spacing $V=3 \mathrm{~m}$, the technological work of the plow is as follows: at the first and second (return), the body is in the extreme position on the right side of the frame (Fig.2, $a$ ). In this case, the plug processes the strip near the protection zone, the width of which is $b_{k}=(B-S) / 6$, where $S-$ is the width of the protection zone. In the first and second transitions, the body is in the extreme right position relative to the frame, i.e., to the right of the axis of symmetry of the tractor. 


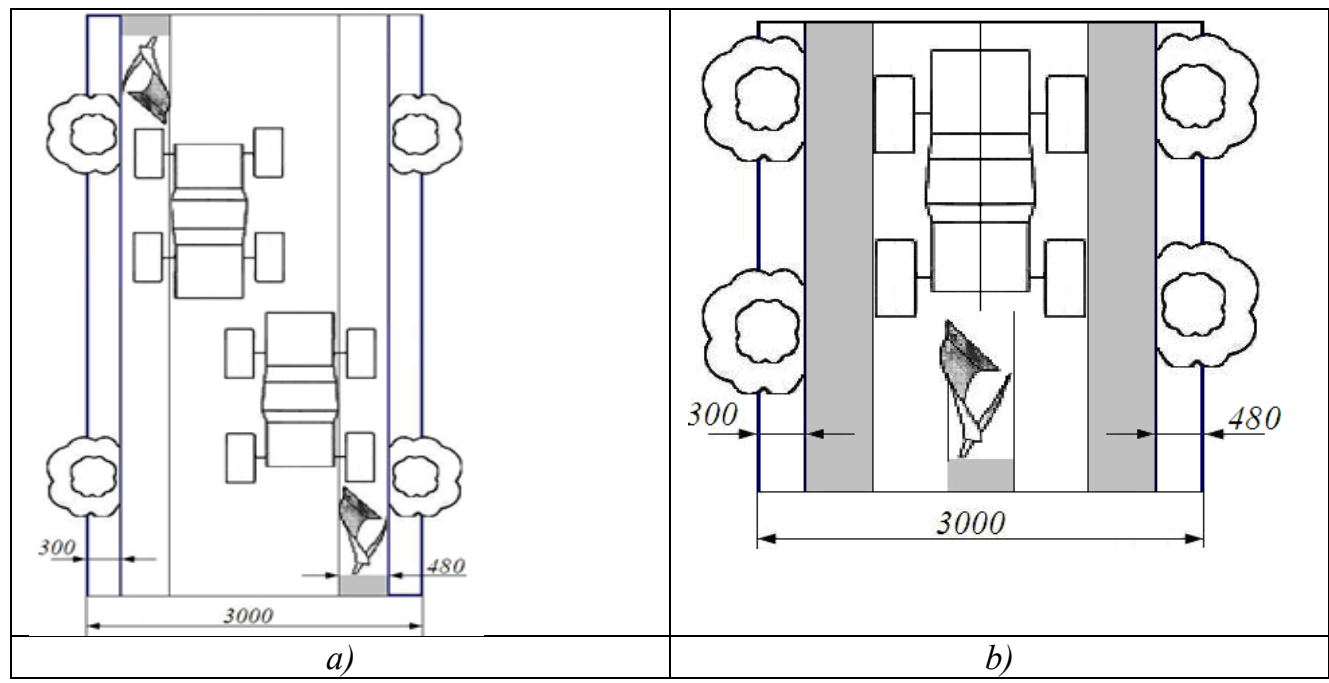

Fig. 2. Diagram of the tractor movement with a single-body plan for processing letters on the side of the protective zone $(a)$ and the silver intercity lane $(b)$

In the third transition (Figure 2, b), the plug handles the middle of the garden row spacing. In this case, the body is placed along the axis of symmetry of the tractor and the fixed frame. In the fourth and fifth transitions (Fig.3), the plug handles the strips between the first and third transitions and the second and third transitions. In this case, the body is moved from the extreme right position of the frame to the left by a distance equal to the coverage width of the body. Thus, the garden is treated evenly between rows.

Depending on the width of the garden row spacing, the coverage width of the hull, the number of passes, and the movement scheme of the unit are selected.

We determine the number of flat plow bodies for tractors of class 0.9 by the following expression

$$
n=\frac{\eta_{t} P}{K b_{k} a},
$$

where $\eta_{t}$ is the coefficient of traction of the tractor; $P$ is rated traction power of the tractor, $\mathrm{N} ; K$ is the specific resistance of the soil to tillage, $\mathrm{Pa} ; a$ is maximum processing depth, $\mathrm{m}$; bk is the coverage width of the case, $\mathrm{m}$.

Assume that the traction force of a 0.9 class wheeled tractor is $9 \mathrm{kN}, \eta_{t}=0.95, K=$ $6.5 \cdot 104 \mathrm{~Pa}$, and the maximum machining depth is $a=0.24 \mathrm{~m}$. When the depth of processing is $20-24 \mathrm{~cm}$, the width of the enclosure of the hulls, which overturns the pallets within the boundaries of its owner, should be in the range $b_{k}=45-52.5 \mathrm{~cm}$. Considering the above, it follows from the expression (2.1) that the number of housings for 0.9 class wheeled tractors is $1.33-1.05$. Therefore, for 0.9 class wheeled tractors, we assume that the number of plow bodies is 1 when the body coverage is in the range of $45-52.5 \mathrm{~cm}$.

\section{Results and Discussion}

In experimental studies, the effect of the coverage width and machining depth of the plug body on its quality characteristics and tensile resistance was studied. In the study, the body coverage width of a single-body plug was changed from 450 to $525 \mathrm{~mm}$ at $25 \mathrm{~mm}$ intervals, and the processing depth was changed from $20 \mathrm{~cm}$ to $26 \mathrm{~cm}$ at $2 \mathrm{~cm}$ intervals. The speed of 
the unit was set at 6 , and $8 \mathrm{~km} / \mathrm{h}$, the distance between the upper and lower attachment points of the suspension device was set at $500 \mathrm{~mm}$, and the vertical distance from the base plane of the plug to the lower attachment point was set at $500 \mathrm{~mm}$.

During the experiments, the width of the housing cover was changed by sliding the seal across the body.

The results of the experiments are shown in Fig.4.

According to experimental studies, the burial rate of plant residues at different processing depths does not differ much from each other depending on the coverage width of the hull, and this figure is at the level of agrotechnical requirements at all coverage widths at processing depths of 20-24 cm (Figure 4). Increasing the coverage width of the hull when the processing depth is $20 \mathrm{~cm}$ decreases the burial rate of plant debris. This can be explained by the fact that at a small processing depth, as the coverage width $b$ increases, the paddle splits into several pieces, mixes, and turns randomly.

According to the results of the experiments, as the coverage width of the body increased at both speeds, its gravitational resistance increased proportionally along the straight line (Fig.4). This can be explained by the fact that as the coverage width increases, the cross-sectional area of the body-treated slab increases.
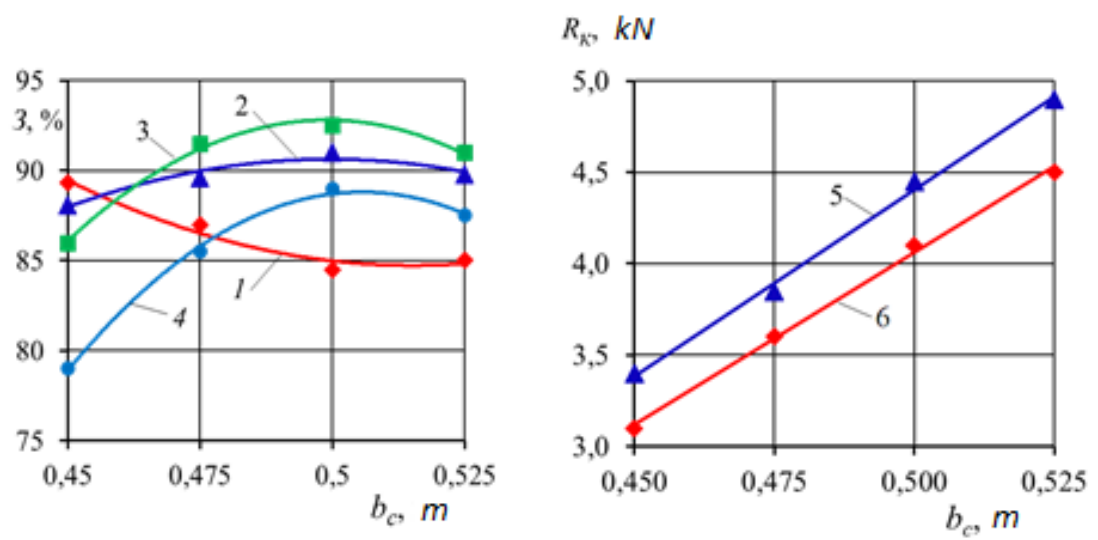

Fig. 4. Graphs of the dependence of the degree of embedding of plant residues $\mathrm{Z}$ and the traction resistance of the housing $R_{c}$ on the width of the body grip: $1-a=20 \mathrm{~cm} ; 1-a=22 \mathrm{~cm} ; 1-a=24 \mathrm{~cm} ; 1-$ $a=26 \mathrm{~cm} ; 5-V=6.24 \mathrm{~km} / \mathrm{soat} ; 6-V=7.64 \mathrm{~km} /$ hour

According to the results of the experiments, as the coverage width of the hull increased at both speeds, the hull resistance of the hull increased proportionally according to the straightline law (Figure 4). This can be explained by the fact that as the coverage width increases, the cross-sectional area of the corrugated plate increases

\section{Conclusions}

1. The technology of cultivating the soil between rows of gardens with a single-body plow for smooth plowing is justified. To implement the proposed technology, the position of the plow body changes relative to the tractor during operation.

2. It is established that when equipping a plow with a movable and fixed frame and performing a body width of $45-52.5 \mathrm{~cm}$, the required plowing quality is achieved with the lowest energy consumption.

3. Single-body plow for smooth plowing with a composite frame for tractors of class 0,6 0,9 allows you to produce high-quality tillage between rows of garden plantings. 


\section{References}

1. Mamatov, F.M., Eshdavlatov, E., Suyunov, A. The Shape of the Mixing Chamber of the Continuous Mixer // Jour of Adv Research in Dynamical \& Control Systems, Vol. 12, 07-Special Issue, (2020). DOI: 10.5373/JARDCS/V12SP7/20202318 ISSN 1943$023 \mathrm{X}$.

2. Mamatov, F., Ergashev, I., Ochilov, S., Pardaev, X. Traction Resistance of Soil Submersibility Type "Paraplau", Jour of Adv Research in Dynamical \& Control Systems, Vol.12, 07-Special Issue, (2020). DOI: 10.5373/JARDCS/V12SP7/20202336 ISSN1943-023X.

3. Aldoshin, N., Mamatov, F., Ismailov, I., Ergashov, G. Development of combined tillage tool for melon cultivation, 19th international scientific conference engineering for rural development Proceedings, Jelgava, (2020). Volume 19. ISSN 1691-5976. DOI:10.22616/ERDev.2020.19.TF175.

4. Umurzakov, U., Mirzaev, B., Mamatov, F., Ravshanov, H., Kurbonov, S. A rationale of broach-plow's parameters of the ridge-stepped ploughing of slopes // XII International Scientific Conference on Agricultural Machinery Industry IOP Conf. Series: Earth and Environmental Science 403(2019) 012163 IOP Publishing doi:10.1088/1755-1315/403/1/012163.

5. Mirzaev, B., Mamatov, F., Chuyanov, D., Ravshanov, X., Shodmonov, G., Tavashov, $\mathrm{R}$ and Fayzullayev, X. Combined machine for preparing soil for cropping of melons and gourds, XII International Scientific Conference on Agricultural Machinery Industry. doi.org/10.1088/1755-1315/403/1/012158.

6. Mirzaev, B., Mamatov, F., Ergashev, I., Ravshanov, H., Mirzaxodjaev, Sh., Kurbanov, Sh., Kodirov, U and Ergashev, G. Effect of fragmentation and pacing at spot ploughing on dry soils // E3S Web of Conferences 97. doi.org/10.1051/e3sconf/201913501065.

7. Mamatov, F., Mirzaev, B., Shoumarova, M., Berdimuratov, P., Khodzhaev, D. Comb former parameters for a cotton seeder, International Journal of Engineering and Advanced Technology (IJEAT), 9(1)

8. Mamatov, F., Mirzaev, B., Batirov, Z., Toshtemirov, S., Tursunov, O., Bobojonov, L. Justification of machine parameters for ridge forming with simultaneous application of fertilizers, IOP Conf. Series: Materials Science and Engineering 883(2020), IOP doi:10.1088/1757-899X/883/1/012165.

9. Mirzaev, B., Mamatov, F., Avazov, I., Mardonov, S. Technologies and technical means for anti-erosion differentiated soil treatment system, E3S Web of Conferences. doi.org/10.1051/e3sconf/20199705036.

10. Aldoshin N., Didmanidze O., Mirzayev B., Mamatov F. Harvesting of mixed crops by axial rotary combines, Proceeding of $7^{\text {th }}$ International Conference on Trends in Agricultural Engineering 2019. 17 $7^{\text {th }}-20^{\text {th }}$ Prague, Czech Republic, pp.20-26, (2019)

11. Mirzaev, B., Mamatov, F., Aldoshin, N and Amonov, M. Anti-erosion two-stage tillage by ripper, Proceeding of 7th International Conference on Trends in Agricultural Engineering 17th-20th. Prague, Czech Republic. - pp.391-396. September (2019)

12. Mirzaev, B., Mamatov, F., Ergashev, I., Islomov, Yo., Toshtemirov, B., Tursunov O. Restoring degraded rangelands in Uzbekistan // Procedia Environmental Science, № 6. - pp 395-404. (2019).

13. Uzakov Z.U., Mamatov F.M., Begulov O. Implementation of object-oriented Programming technology in the one-dimensional oil displacement problem, International Conference on information Science and Communications Technologies: ICISCT 2019/0012008. Tashkent, Uzbekistan. INSPEC Accession Number: 19412491. DOI: 10.1109/ICISCT47635.2019.9012008.

14. Mamatov, F., Mirzaev, B., Berdimuratov, P., Turkmenov, Kh., Muratov, L., 
Eshchanova, G. The stability stroke of cotton seeder moulder // CONMECHYDRO 2020. IOP Conf. Series: Materials Science and Engineering 883 (2020) 012145 IOP Publishing. doi:10.1088/1757-899X/883/1/012145.

15. Mamatov, F., Mirzaev, B., Tursunov, O. A Justification of Broach-Plow's Parameters of the Ridge-Stepped Ploughing // E3S Web of Conferences 97, 05035 (2019). doi.org/10.1051/e3sconf/20199705035.

16. Ahmedov B.J., Mirzaev, B.S.,Mamatov, F.M., Khodzhaev, D.A., Julliev, M.K. Integrating of gis and gps for ionospheric perturbations in d- And f-layers using vlf receiver // InterCarto, InterGIS 26, - c. 547-560. DOI: 10.35595/2414-9179-2020-1-26547-560.

17. Mamatov, F., Mirzaev, B., Tursunov, O., Ochilov, S and Chorieva, D. Relief, physicomechanical and technological properties of soil in the cotton growing area // ICECAE 2020. IOP Conf. Series: Earth and Environmental Science 614(2020) 012169. IOP Publishing. doi:10.1088/1755-1315/614/1/012169.

18. Shamsutdinov, Z., Ubaydullaev, Sh., Shamsutdinov, N., Mirzaev, B., Mamatov, F., and Chorshabiyev, N. The concept of the phytogenic field: theory, research experience and practical significance // ICECAE 2020. IOP Conf. Series: Earth and Environmental Science 614(2020) 012164. IOP Publishing. doi:10.1088/1755-1315/614/1/012164.

19. Umurzakov, U., Mamatov, F., Aldoshin, N., and Mirzaev, B. Exploration of tillage technologies in the Republic of Uzbekistan // ICECAE 2020 IOP Conf. Series: Earth and Environmental Science 614(2020) 012168. IOP Publishing. doi:10.1088/17551315/614/1/012168.

20. Mamatov, F., Aldoshin, N., Mirzaev, B., Ravshanov, H., Kurbanov, Sh and Rashidov, N. Development of a frontal plow for smooth, furless plowing with cutoffs // IPICSE 2020. IOP Conf. Series: Materials Science and Engineering 1030 (2021) 012135 IOP Publishing. doi:10.1088/1757-899X/1030/1/012135.

21. Mamatov, F., Mirzaev, B., Mirzahodzhaev, Sh., Uzakov, Z and Choriyeva, D. Development of a front plow with active and passive working bodies // IPICSE 2020. IOP Conf. Series: Materials Science and Engineering 1030 (2021) 012164. IOP Publishing. doi:10.1088/1757-899X/1030/1/012164.

22. Mamato, F.M., Eshdavlatov, E., Suyuno, A. Continuous Feed Mixer Performance //Journal of Advanced Research in Dynamical and Control Systems (JARDCS). Volume-12, 07-Spesia1 Issue, 2020. DOI: 10.5373/JARDCS/V12SP7/20202343. ISSN 1943-023X.

23. Mamatov, F., Ergashev, I., Mirzaev, B., Pardaev, X, Chorieva, D. Research of the Penetration Process of the Frontal Plow // 2nd Bukittinggi International Conference on Education (BICED) 2020. Journal of Physics: Conference Series 1779 (2021) 012002. IOP Publishing. doi:10.1088/1742-6596/1779/1/012002.

24. Mamatov F.M., Mirzaev B.S., Avazov I.Zh.. Agrotehnicheskie osnovy sozdanija protivojerozionnyh vlagosberegajushhih tehnicheskih sredstv obrabotki pochvy $\mathrm{v}$ uslovijah Uzbekistana // - Prirodoobustrojstvo, (2014).

25. Mamatov F.M., Mirzaev B.S. Erosion preventive technology of crested ladder-shaped tillage and plow design // European Applied Sciences. Stuttgart (Germany),- pp. 7173. (2014).

26. Lobachevskij Ja.P., Mamatov F., Jergashev I.T. Frontal'nyj plug dlja hlopkovodstva // - Hlopok, № 6. pp- 35-37. (1991).

27. SackunV.A, LobachevskyY.P., Sizov O.A., SharovV.V. New Technology and Eguipment for Level Ploughing Silsoe Research Institute. Translation. - №34. Silsoe, England, - pp.1-7. (1991). 